\title{
Assessing Soil Tolerance Limit for Two Soil Orders Surrounding Sulaimani City
}

\author{
Marwa Abubakr Ahmed \\ Natural Resources Department \\ College of Agricultural Engineering Sciences \\ University of Sulaimani \\ Sulaimani, Iraq \\ Marwa.ahmed@univsul.edu.iq
}

\author{
Kamal Sharif Qadir \\ Natural Resources Department \\ College of Agricultural Engineering Sciences \\ University of Sulaimani \\ Sulaimani, Iraq \\ Kamal.qadir@univsul.edu.iq
}

Volume 4 - Issue 2

December 2019

DOI:

10.24017/science.2019

.2 .18

Received:

03 November 2019

Accepted:

27 December 2019

\begin{abstract}
This research was conducted to determined Soil loss tolerance limit (SLTL) which used for soil and water conservation projects and assessing the potential risk of soil erosion. In this study, two different sites were selected including Bakrajo and Qallachwalan were located 9.4 and $23.7 \mathrm{~km}$ far from Sulaimani city respectively. The soil orders in the two studied sites were determined through describing the soil profile properties which were known as Vertisols and Mollisols respectively. Each site was divided into 16 sub-sites using the grid point system. The dimension of each site was $(2.5 * 2.5 \mathrm{~km})$. The estimated soil tolerance limit for whole grid points except one grid point at Bakrajo site was equal to 12.5 ( $\mathrm{Mg} / \mathrm{ha} / \mathrm{yr}$ ), while at Qallachwalan in a wide range as $2.5-10(\mathrm{Mg} / \mathrm{ha} / \mathrm{yr})$. The mentioned results of soil tolerance limit explained that the Bakrajo site is more resist to the risk of water erosion compared to Qallachwalan site which was known as a rugged area. Besides the most soil depth of the grid points at Qallachwalan was shallow did not exceed $50 \mathrm{~cm}$. So the Qallachwalan site needs several processes conservation planning than the Bakrajo site which known as more deep and flatty soil.
\end{abstract}

Keywords: Soil loss tolerance limit, biophysical model, land degradation, soil erosion, soil erodibility factor, saturation hydraulic conductivity. 


\section{INTRODUCTION}

Degradation can cause unacceptable land use for pasture, agricultural, industrial or urban purposes by reducing the yield potential and the soil quality[1]. In fact, a degradative process such as biological, chemical and physical leads to decrease soil productivity and quality. The food security and consequently the world population now and in the future depend on sustainability[2]. Sustainable land management practices are needed to avoid land degradation which typically occurs because of human development or land management practices that is not sustainable over a period[3].

In the many parts of the world, land degradation is rising in intensity and extent, as for grasslands, cultivated areas and forests, the rate of $(10,20$ and 30)\% has been reported subjected to degradation[4]. Erosion is one of the most recognized and dominant types of soil degradation causes remove the most nutrient rich and organic matter dense layer of the soil profile [5]. In various parts of the world, soil erosion is accelerated such as the area under study due to population density, deforestation, overgrazing, intensive land cultivation and higher demand for firewood as an energy source $[6,7]$.

In the developing counties especially in the tropics and subtropics areas subjected to soil degradation is a permanent issue and going to stay the same during the twenty- one century, whilst, soil degradation occurs by accelerated erosion [8]. Gabriels and Conelis [9] demonstrated that land degradation covers the soil, vegetation and water resources degradation and water erosion is the most important type of soil degradation occupying fifty six percent of the worldwide area. Conacher, [10] showed that salinization and waterlogging of irrigated areas are two closely related and perhaps the earliest forms of reported land degradation.

Soil erosion is a slow dynamic natural process which involves detachment, transportation and accumulation of productive surface soil across the earth's surface through water or wind action[11]. Pimentel [12] demonstrated that soil low organic matter content, medium to fine texture and weak structural development is very easy to erosion. Also, soils which have low water infiltration rate are subject to high rates of erosion by water and the soil particles are easily displaced by wind power. Gupta et al., [13] showed many other issues created by soil erosion such as deposition of unfertile materials on cultivated lands, harmful effects on water supply, sedimentation of canals and rivers and most important the destruction of the agricultural fertile lands. In addition, crop productivity decreases by soil erosion, due to either physical degradation or nutrient depletion[14]. Some index cause soil erosion such as soil surface crusts increasing, opened roots, the reduced topsoil thickness, apparent gullies or rills, opened subsoil at the soil surface and poor plant growth [15].

Determination of soil erosion can be helpful for improving the information about the extent of the areas influenced and consequently for developing measurement due to reduce the intensity of the issue by recognition of areas that are severely affected. As reported by [16, 17] appropriate land management along with technologies such as soil conservation methods cause increasing in land productivity, reducing soil erosion and sustain soil quality.

Duan et al., [18] discovered the determination of the soil loss tolerance limit (SLTL or T value) is one of the most important aspects of water and soil conservation projects leads to a criterion for controlling erosion rates. Mandal and Sharda [19] defined soil loss tolerance as the maximum rate of erosion at which the quality of a soil as a medium for plant growth can be maintained. On the other definition, SLT defined as the maximum amount of annual soil erosion that will permit a high level of crop productivity to be obtained economically over an extended period of time [20]. These authors suggested various criteria should be considered in the evaluating of SLT, including influence on water quality, grade or (class) of weathering and modify in soil quality. Method conserving the nonlinearities of soil growth or (progression) process and weathering of the rock should be displaced of a direct association between evolution of the soil profile and soil erosion by [21]. Therefore, Lal [22] suggested that the TSL concept should be extended involve the environmental influence of air quality and water on ecosystems and the greenhouse effect economic effects of onsite and offsite, the amount of soil erosion and the amount of new soil formation. 
Mostly depends on the proficiency of the individuals included for determining soil loss tolerance limit (SLTL), despite the consequence of STL for soil conservation. For estimating SLT Duan et al.,[18] reported three major quantitative methods based on soil formation rate, soil thickness and soil productivity.

The SLT is based on favorable rooting depth as reported by [23]. Lenka et al., [24] recommended that SLTL estimation can be calculated based on soil functions. This is affects soil erosion process. In addition, the best approximation of SLT can be estimated by the root zone rather than the depth of the root [24]. However, SLTL of (13 ton/ha/yr) has been proposed for deep medium textured soils under moderate humid conditions at the time amount of soil loss is believed to take pace with the comparable amount of weathering [25].

The United State Department of Agriculture in 1956 reported ten factors which have an impact on SLTL. This is for special soil involving soil depth, likelihood of appear gully and rill, the formation of the soil from parent material, erosion cause to loss plant nutrients, reduction of crop yield by erosion, converts favorable soil properties for plant growth which caused by erosion, the rate topsoil formation from subsoil, delivery of sediment from the erosion site, over and above maintainable soil conservation practices on the availability of economic, practicable, artistic and socially tolerable [18].

Quantifying the acceptable soil loss without influencing is a major challenge for planner, researchers and conservationists [19]. Mandal et al., [26] elucidated that on shallow soils SLTL land productivity declines quickly when SLTL is $5 \mathrm{Mg} / \mathrm{ha} / \mathrm{yr}$. Conversely, crop productivity not affected in deep soils when soil loss tolerance limit (12.5 Mg/ha/yr). With a few exceptions, the SLTL for 12 sub-watersheds within Chamchamal main catchment was estimated at $10 \mathrm{Mg} / \mathrm{ha} / \mathrm{yr}$ [7]. On the other hand, Hussein, [27] noticed that about $43 \%$ out of 49 sites within Bastora catchment had SLTL of $12.5 \mathrm{Mg} / \mathrm{ha} / \mathrm{yr}$ on account of the sufficient soil depth and high soil resistivity to erosion.

The most important factor for determined soil loss tolerance limit refers to considered soil formation rate[28]. Therefore, standard SLTL value based on soil formation rates in most farmlands, but it's not reasonable to utilize[19].

Thus, the objective of the research was to find and compare permissible soil loss limit for two orders study sites in Sulaimani city.

\section{METHODS AND MATERIALS}

Two different sites were selected according to their different in soil orders in June-September 2018. The selected sites were Bakrajo (Vertisols) is located between N 35 29' 45" and N $35^{\circ}$

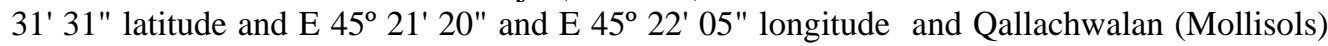

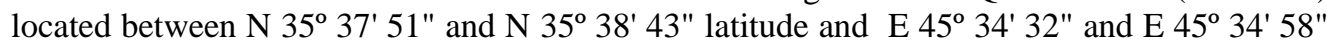
longitude (Fig. 1).

A biophysical model described by Mandal and Sharda[19] was employed to STL for different grid points of a grid system $\left(2.5^{*} 2.5 \mathrm{~km}\right)$. For these reason five indicators, each representing a soil function related to soil erosion was selected including saturated hydraulic conductivity, soil erodibility, soil organic matter content, soil bulk density and soil $\mathrm{pH}$. The calculated value of each index was converted to a unitless score ranged between zeros to one. Based on the relative importance of the indicator, weights were applied to the indexes. The weights to the five indicators that mentioned before were $0.35,0.25,0.10,0.15$ and 0.15 respectively[19]. Then the transformed values of the indicators scaled " 0 to 1 " scale were multiplied by (the weight) assigned to them.

A quantitative value $(\mathrm{Q})$ indicating the aggregate score was obtained for the each grid point by collecting the values of the weighted parameters as described below:

$Q=\sum_{i=1}^{n} q i w i$

$$
Q=q_{\text {rir }} w_{w i r}+q_{r k} w_{w k}+q_{r b d} w_{w b d}+q_{r o c} w_{w o c}+q_{r p H} w_{w p H}
$$


Where: Q defines (the state or condition) of the soil in terms of (structural and functional) integrity, $q_{\text {rir }}$ index for infiltration rate, $q_{r k}$ the rating for( soil erodibility), $q_{r b d}$ used for the bulk density, $q_{\text {roc }}$ used for the organic carbon and $q_{\mathrm{rpH}}$ the rating for potential of hydrogen $(\mathrm{pH})$ of soils and $(\mathrm{W})$ indicates the weight factor for each function.

According to the $\mathrm{Q}$ value, there are three groups of soil: $1(\mathrm{Q}<0.33), 2(Q=0.33+0.66)$, and $3(\mathrm{Q}>0.66)$. The STL was computed for each grid point on the basis of soil group multiply depth matrix [29].

The soil erodibility at each grid points was estimated using the following equation [30].

$$
K=0.27710^{-5} M^{1.14}(12-\mathrm{OM})+0.043(\mathrm{SC}-2)+0.033(\mathrm{PC}-3)
$$

Where:

$\mathrm{K}=$ soil erodibility in metric unit $\left(\mathrm{hr} \mathrm{m}^{-1} \mathrm{~cm}^{-1}\right)$

$\mathrm{M}=(100-$ clay $\%)($ silt $\%$ + very fine sand $\%)$

$\mathrm{OM}=$ organic matter $\%$;

$\mathrm{SC}=$ structure class code, showed in (Table 1).

PC = permeability class code, showed in (Table 2).

Also representative soil samples were obtained from the top $(0.20 \mathrm{~m})$ at each grid points. They were air-dried (at $48 \mathrm{hr}$. to take laboratory condition), grounded by plastic hummer and sieved with No, $\leq 2 \mathrm{~mm}$ due determine particle size distribution by using sieving method according to[31]. The structure was described visually after dropping representative clods from a height of about $1 \mathrm{~m}$ in the field. Constant head permeameter method used to determine soil hydraulic conductivity for undisturbed cores diameter was $(10 \mathrm{~cm})$ and the length was $(10 \mathrm{~cm})$, following the procedure reported by[31]. The soil bulk density was measured by clod method covering with paraffin wax as described by[32]. Wet oxidation method was applied for measuring soil organic carbon content as described by [33]. The $\mathrm{pH}$ of the soil saturation extract (soil to water ratio 1:1) was measured with $\mathrm{pH}$-meter (Hanna $\mathrm{pH}$ 211, model) according to[34].

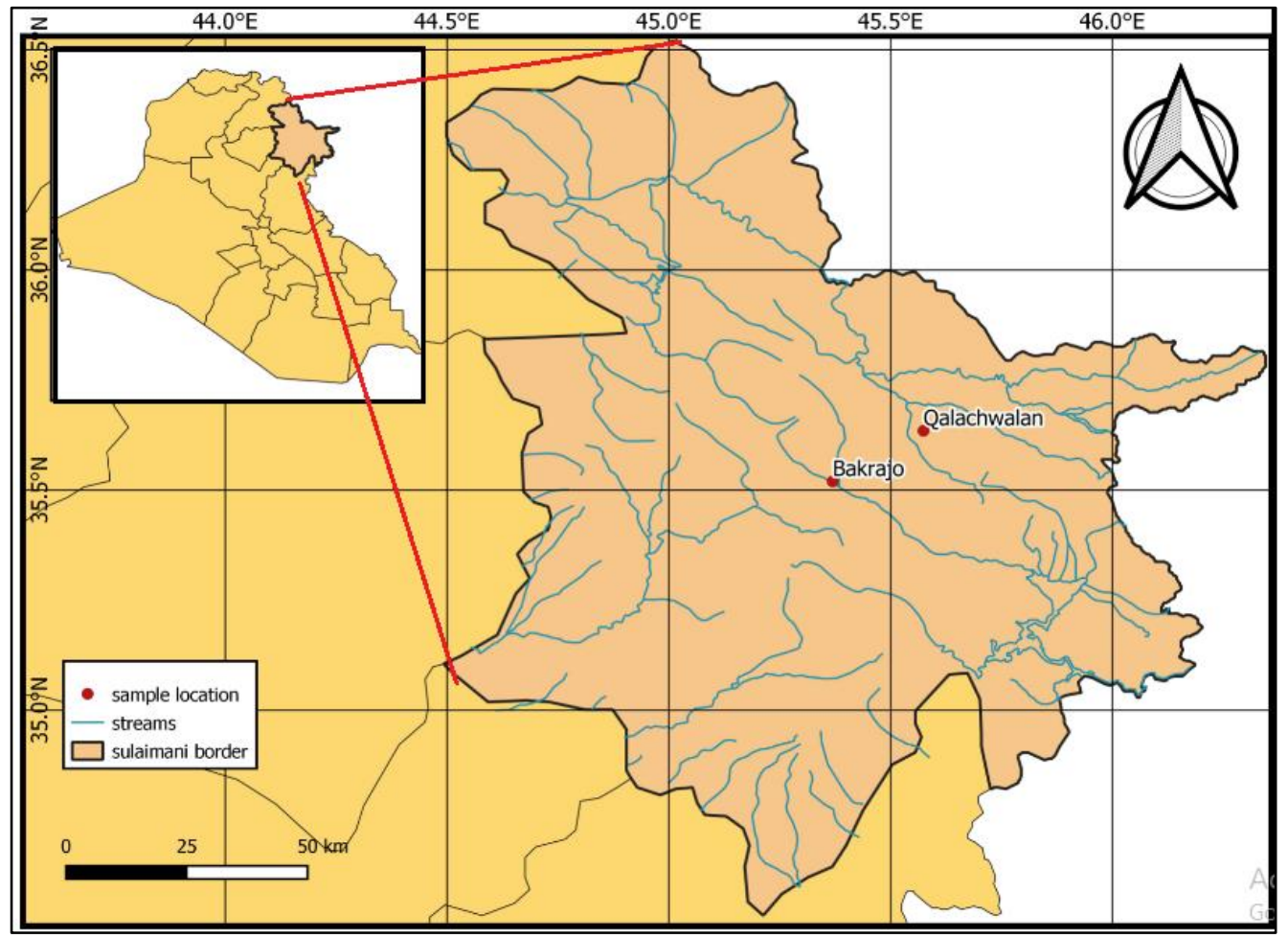

Figure 1: Location map showing study site 
Table 1: Structure code (SC) for structure types

\begin{tabular}{ll}
\hline Type of structure & SC \\
\hline Very fine granular structure & 1 \\
\hline Fine granular structure & 2 \\
\hline Medium or coarse granular structure & 3 \\
\hline Blocky, platy or columnar structure & 4 \\
\hline
\end{tabular}

Table 2: Permeability code (PC) for permeability classes

\begin{tabular}{lll}
\hline Permeability $\left(\mathbf{c m ~ h r}^{-1}\right)$ & Permeability class & PC \\
\hline$<0.1$ & Very slow & 6 \\
\hline $0.1-0.5$ & Slow & 5 \\
\hline $0.5-2$ & Slow to moderate & 4 \\
\hline $2-6$ & Moderate & 3 \\
\hline $6-12$ & Moderate to rapid & 2 \\
\hline$>12$ & Rapid & 1 \\
\hline
\end{tabular}

\section{RESULTS AND DISCUSSION}

\subsection{Soil erodibility estimation factor $(K)$}

Value of the K-factor were computed for different grid points for Bakrajo and Qallachwalan sites according to the method which prepared by[35]. Table 3 shows the results. The K-values ranged from 0.249 to 0.483 for grid points 1 and 13 in Bakrajo respectively, for Qallachwalan ranged from 0.181 to 0.493 metric units at grid points 4 and 11 respectively. Results show that, even there was little variation in K-value at the study sites, but still at Qallachwalan was greater compared to Bakrajo site, due to topography of Qallachwalan had slope and rugged, while the other site was approximately flat. However, clay content ranged $32.33 \%$ and $46.99 \%$ for Bakrajo, and $15.08 \%$ and $61.08 \%$ for Qallachwalan and soil organic matter content which ranged between $1.35 \%$ and $3.11 \%$ at Bakrajo but $0.22 \%$ to $4.17 \%$ at Qallachwalan. It was also found that clay content and organic matter was linearly and negatively correlated with Kvalue, indicating that as clay content increases, the $\mathrm{K}$-value decreases, and the greater the amount of organic matter, the lower will be the $\mathrm{K}$-value. These results are closed were conducted in Chamchamal, Erbil and Sulaimani by [7, 27, 36] respectively.

Table 3: Soil erodibility factor for Bakrajo and Qallachwalan sites

\begin{tabular}{|c|c|c|c|c|c|c|c|c|c|}
\hline \multirow{2}{*}{$\stackrel{\triangleq}{\text { 竞 }}$} & \multirow{2}{*}{ 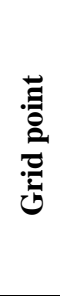 } & \multicolumn{3}{|c|}{$\begin{array}{c}\text { Particle size distribution } \\
(\%)\end{array}$} & \multirow{2}{*}{ 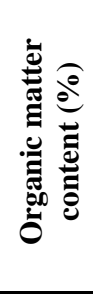 } & \multirow{2}{*}{ 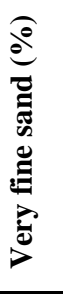 } & \multirow{2}{*}{ 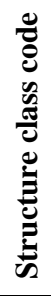 } & \multirow{2}{*}{ 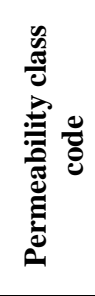 } & \multirow{2}{*}{ 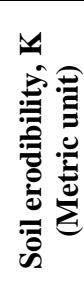 } \\
\hline & & ङ & 击 & 己 & & & & & \\
\hline \multirow{5}{*}{ 赵 } & 1 & 8.00 & 45.01 & 46.99 & 2.21 & 1.54 & 4 & 2 & 0.249 \\
\hline & 2 & 2.68 & 55.01 & 42.31 & 2.21 & 1.44 & 4 & 2 & 0.327 \\
\hline & 3 & 7.74 & 55.94 & 36.32 & 1.69 & 2.15 & 4 & 4 & 0.482 \\
\hline & 4 & 5.40 & 61.43 & 33.17 & 1.88 & 1.94 & 4 & 3 & 0.471 \\
\hline & 5 & 8.41 & 55.74 & 35.85 & 3.11 & 3.15 & 4 & 3 & 0.379 \\
\hline
\end{tabular}




\begin{tabular}{|c|c|c|c|c|c|c|c|c|c|}
\hline & 6 & 4.50 & 58.61 & 36.89 & 2.02 & 1.51 & 4 & 3 & 0.415 \\
\hline & 7 & 7.04 & 55.89 & 37.07 & 1.49 & 2.78 & 4 & 2 & 0.389 \\
\hline & 8 & 3.76 & 62.49 & 33.75 & 1.97 & 1.91 & 4 & 3 & 0.467 \\
\hline & 9 & 3.76 & 50.25 & 45.99 & 1.99 & 1.61 & 4 & 3 & 0.326 \\
\hline & 10 & 2.78 & 54.39 & 42.83 & 1.65 & 1.35 & 4 & 2 & 0.333 \\
\hline & 11 & 5.22 & 56.81 & 37.97 & 1.75 & 2.11 & 4 & 2 & 0.381 \\
\hline & 12 & 5.16 & 56.70 & 38.14 & 1.35 & 1.78 & 4 & 4 & 0.459 \\
\hline & 13 & 4.36 & 63.31 & 32.33 & 1.82 & 1.99 & 4 & 3 & 0.483 \\
\hline & 14 & 6.44 & 51.10 & 42.46 & 2.77 & 2.27 & 4 & 1 & 0.259 \\
\hline & 15 & 4.69 & 60.84 & 34.47 & 1.67 & 2.01 & 4 & 3 & 0.468 \\
\hline & 16 & 3.82 & 54.09 & 42.09 & 2.17 & 1.65 & 4 & 3 & 0.361 \\
\hline \multirow{16}{*}{ 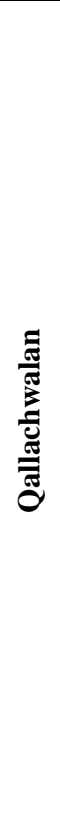 } & 1 & 17.59 & 36.62 & 45.79 & 2.32 & 1.87 & 4 & 4 & 0.284 \\
\hline & 2 & 11.37 & 37.14 & 51.49 & 1.69 & 3.02 & 4 & 4 & 0.284 \\
\hline & 3 & 10.11 & 37.52 & 52.37 & 3.22 & 1.89 & 4 & 2 & 0.185 \\
\hline & 4 & 31.59 & 28.78 & 39.63 & 3.99 & 4.09 & 4 & 2 & 0.181 \\
\hline & 5 & 4.77 & 34.15 & 61.08 & 1.95 & 1.23 & 4 & 4 & 0.229 \\
\hline & 6 & 14.57 & 37.32 & 48.11 & 3.82 & 3.87 & 4 & 3 & 0.225 \\
\hline & 7 & 25.47 & 44.12 & 30.41 & 3.63 & 4.73 & 2 & 2 & 0.209 \\
\hline & 8 & 10.99 & 45.36 & 43.65 & 4.07 & 2.06 & 4 & 2 & 0.228 \\
\hline & 9 & 21.82 & 54.44 & 23.74 & 2.11 & 5.59 & 4 & 2 & 0.459 \\
\hline & 10 & 9.91 & 53.14 & 36.95 & 2.05 & 2.11 & 4 & 3 & 0.382 \\
\hline & 11 & 7.32 & 59.41 & 33.27 & 0.99 & 2.22 & 4 & 3 & 0.493 \\
\hline & 12 & 42.17 & 40.07 & 17.76 & 0.22 & 13.59 & 3 & 2 & 0.469 \\
\hline & 13 & 11.80 & 41.99 & 46.21 & 1.61 & 2.06 & 4 & 3 & 0.283 \\
\hline & 14 & 8.25 & 57.11 & 34.64 & 0.48 & 1.94 & 2 & 4 & 0.425 \\
\hline & 15 & 43.19 & 35.21 & 21.60 & 4.17 & 6.45 & 3 & 2 & 0.229 \\
\hline & 16 & 61.38 & 23.54 & 15.08 & 1.33 & 9.38 & 4 & 1 & 0.276 \\
\hline
\end{tabular}

\subsection{Soil indicators used for assessing soil loss tolerance limit}

Table (4) displays the measured values for four soil indicators at the grid points of the system which was established. These indicators were selected based on sensitivity analysis. Each indicator represents a soil function related to soil erosion.

According to the table 4 the saturated hydraulic conductivity varies from a minimum of 0.72 $\mathrm{cm} \mathrm{hr}^{-1}$ at grid point 12 to a maximum of $14.40 \mathrm{~cm} \mathrm{hr}^{-1}$ at the grid 14 at Bakrajo site, but in Qallachwalan site those values ranged from 0.90 and $18.36 \mathrm{~cm} \mathrm{hr}^{-1}$ at grid points 5 and 16 respectively. The variation of saturated hydraulic conductivity may cause by variation in soil bulk density and soil texture. These results are in concord with the results obtained by [27] in Erbil.

It can also be noticed that the soil bulk density ranged from $1.41 \mathrm{Mg} \mathrm{m}^{-3}$ at grid point 1 and $1.69 \mathrm{Mg} \mathrm{m}^{-3}$ at grid point 12 within Bakrajo site, but at Qallachwalan site were 1.38 and 1.70 $\mathrm{Mg} \mathrm{m}^{-3}$ at grid points 5 and 16 respectively.

A considerable difference in soil organic carbon content values can be observed across the entire both sites, which varied from $0.78 \%$ at grid point 12 to $1.80 \%$ at grid point 5 for Bakrajo site and in Qallachwalan ranged from $0.13 \%$ at grid point 12 to 2.42 at grid point 15 . Overall the soils of the study areas are described by low soil organic matter. The soil of the 
majority sites fell in the high soil organic matter content class $\mathrm{OM}>12.9 \mathrm{~g} \mathrm{~kg}^{-1}$ propsed by [37].

The results of the study sites also indicated that soil $\mathrm{pH}$ was ranged between 7.27 at grid point 1 to 8.08 at grid point 11 for Bakrajo site, but in Qallachwalan was ranged from 7.05 at grid point 4 to 7.85 in grid point 14 . The $\mathrm{pH}$ of majority of the soil fell in neutral class (7.4-7.8), while the $\mathrm{pH}$ of the remaining soils fell in the moderately alkaline class (6.6-7.3) by [38].

Table 4: Soil indicators used for describing the resistance of soil to water erosion at the two study sites

\begin{tabular}{|c|c|c|c|c|c|}
\hline Site & $\begin{array}{l}\text { Grid } \\
\text { point }\end{array}$ & $\begin{array}{l}\text { Saturated hydraulic } \\
\text { conductivity }\left(\mathrm{cm} \mathrm{hr}^{-1}\right)\end{array}$ & $\begin{array}{l}\text { Bulk density } \\
\left(\mathrm{Mg} \mathrm{m}^{-3}\right)\end{array}$ & $\begin{array}{l}\text { Soil organic } \\
\text { carbon }(\%)\end{array}$ & Soil pH \\
\hline \multirow{16}{*}{ 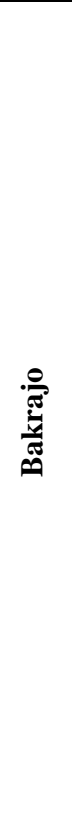 } & 1 & 10.08 & 1.41 & 1.28 & 7.27 \\
\hline & 2 & 8.28 & 1.52 & 1.28 & 7.92 \\
\hline & 3 & 1.08 & 1.60 & 0.98 & 7.81 \\
\hline & 4 & 3.60 & 1.54 & 1.09 & 7.80 \\
\hline & 5 & 3.96 & 1.47 & 1.80 & 7.54 \\
\hline & 6 & 3.24 & 1.51 & 1.17 & 7.92 \\
\hline & 7 & 7.20 & 1.54 & 0.87 & 7.91 \\
\hline & 8 & 2.16 & 1.64 & 1.14 & 7.87 \\
\hline & 9 & 3.60 & 1.44 & 1.15 & 7.82 \\
\hline & 10 & 6.12 & 1.47 & 0.96 & 7.83 \\
\hline & 11 & 7.20 & 1.48 & 1.02 & 8.08 \\
\hline & 12 & 0.72 & 1.69 & 0.78 & 7.89 \\
\hline & 13 & 5.76 & 1.56 & 1.06 & 7.96 \\
\hline & 14 & 14.40 & 1.42 & 1.60 & 7.88 \\
\hline & 15 & 2.52 & 1.50 & 0.97 & 7.89 \\
\hline & 16 & 3.60 & 1.49 & 1.26 & 7.86 \\
\hline \multirow{16}{*}{ 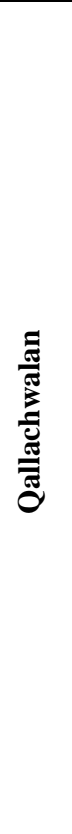 } & 1 & 1.80 & 1.50 & 1.35 & 7.46 \\
\hline & 2 & 1.44 & 1.43 & 0.98 & 7.65 \\
\hline & 3 & 8.64 & 1.47 & 1.87 & 7.48 \\
\hline & 4 & 7.20 & 1.50 & 2.32 & 7.05 \\
\hline & 5 & 0.90 & 1.38 & 1.13 & 7.51 \\
\hline & 6 & 2.57 & 1.48 & 2.22 & 7.34 \\
\hline & 7 & 8.64 & 1.49 & 2.11 & 7.27 \\
\hline & 8 & 11.16 & 1.55 & 2.36 & 7.24 \\
\hline & 9 & 8.28 & 1.54 & 1.23 & 7.40 \\
\hline & 10 & 5.40 & 1.53 & 1.19 & 7.77 \\
\hline & 11 & 4.32 & 1.58 & 0.57 & 7.78 \\
\hline & 12 & 7.20 & 1.60 & 0.13 & 7.76 \\
\hline & 13 & 5.76 & 1.48 & 0.93 & 7.57 \\
\hline & 14 & 1.44 & 1.64 & 0.28 & 7.85 \\
\hline & 15 & 10.8 & 1.56 & 2.42 & 7.16 \\
\hline & 16 & 18.36 & 1.70 & 0.77 & 7.80 \\
\hline
\end{tabular}




\subsection{Soil tolerance limit}

Table (5) shows the calculate of aggregate score from the attributed scores and the corresponding weights. It is obvious that the aggregate score is distributed in a wide range, and varied from 0.410 at grid point 12 and 0.900 at grid points 1 and 14 within Bakrajo site. With some exception the aggregate score of most grid points $(1,2,4,5,7,9,10,11,13,14$, and 16) were exceed $0.66 \mathrm{q} 6$ demonstrating soil good state as a result all of the these soils were placed in group $3(\mathrm{Q}>0.66)$. But aggregate scores at grid points $(3,6,8,12$, and 15$)$ were ranged between 0.33 and 0.66 and placed in group 2 showing soils are in moderate state. The aggregate scores for Qallachwalan site were ranged between 0.400 to 0.930 at grid points 14 and 3 respectively. With some exception, the aggregate scores of most grid points of $(3,4$, $6,7,8,9,10,13,15$ and 16) also were exceed 0.66 and were placed in group 3 , but the remain aggregate scores at grid points of $1,2,5,11,12$, and 14 were falling between 0.33 and 0.66 and placed in group 2 .

Finally the STL for the two study sites was calculated based on soil group multiply by depth matrix. The STL for Bakrajo site at the all investigated grid points was estimated of $12.5 \mathrm{Mg}$ $\mathrm{ha}^{-1} \mathrm{yr}^{-1}$, except grid point 1 which was $7.5 \mathrm{Mg} \mathrm{ha}^{-1} \mathrm{yr}^{-1}$ (table 6). Soil loss tolerance limit at grid point 1 can be related to the soil depth which was about $25-50 \mathrm{~cm}$, while the soil depth for remained grid points was above $150 \mathrm{~cm}$. These results reflect that the existing soils over the study site are characterized by relatively low heterogeneity with respect to ( infiltration rate, soil bulk density, soil organic carbon, soil $\mathrm{pH}$, soil erodibility and soil depth ).

The estimated STL in Qallachwalan site was distributed a wide range and varied between 2.5 $\mathrm{Mg} \mathrm{ha}^{-1} \mathrm{yr}^{-1}$ at grid points 12 and 14 , to $10 \mathrm{Mg} \mathrm{ha}^{-1} \mathrm{yr}^{-1}$ at grid point 1,3 and 4 . The main reason for existing a wide range of STL in Qallachwalan is that the study site had the different soil depth ranged between $<25 \mathrm{~cm}$ to $150 \mathrm{~cm}$. So Qallachwalan site needs special conservation practices than Bakrajo site such as afforestation, pasture management and preventing the trees and grasses from burning cutting, pasture management, preventing the trees and grasses from burning cutting. Similar results were reported by [27] in Erbil and [39] for three states of northern India.

Table 5: calculation of aggregate score from the individual rate for different attribute

\begin{tabular}{|c|c|c|c|c|c|c|c|}
\hline \multirow[b]{2}{*}{ Site } & \multirow[b]{2}{*}{$\begin{array}{l}\text { Grid } \\
\text { points }\end{array}$} & \multicolumn{6}{|c|}{ Individual rate for } \\
\hline & & $\begin{array}{l}\text { Saturated } \\
\text { hydraulic } \\
\text { conductivity } \\
\text { (q1) }\end{array}$ & $\begin{array}{l}\text { Bulk } \\
\text { density } \\
\text { (q2) }\end{array}$ & $\begin{array}{l}\text { Soil } \\
\text { erodibility } \\
\text { (q3) }\end{array}$ & $\begin{array}{l}\text { Organic } \\
\text { carbon } \\
(q 4)\end{array}$ & $\begin{array}{l}\text { Soil pH } \\
\text { (q5) }\end{array}$ & $\begin{array}{l}\text { Aggregate } \\
\text { score (q6) }\end{array}$ \\
\hline \multirow{14}{*}{ 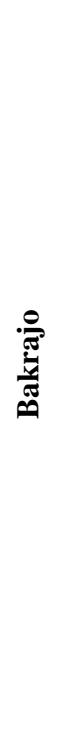 } & 1 & 1 & 0.8 & 0.8 & 0.8 & 1 & 0.900 \\
\hline & 2 & 1 & 0.5 & 0.5 & 0.8 & 0.8 & 0.765 \\
\hline & 3 & 0.3 & 0.3 & 0.5 & 0.5 & 0.8 & 0.455 \\
\hline & 4 & 0.8 & 0.5 & 0.5 & 0.8 & 0.8 & 0.695 \\
\hline & 5 & 0.8 & 0.8 & 0.5 & 1 & 0.8 & 0.755 \\
\hline & 6 & 0.5 & 0.5 & 0.5 & 0.8 & 0.8 & 0.590 \\
\hline & 7 & 1 & 0.5 & 0.5 & 0.5 & 0.8 & 0.720 \\
\hline & 8 & 0.5 & 0.2 & 0.5 & 0.8 & 0.8 & 0.560 \\
\hline & 9 & 0.8 & 0.8 & 0.5 & 0.8 & 0.8 & 0.725 \\
\hline & 10 & 1 & 0.8 & 0.5 & 0.5 & 0.8 & 0.750 \\
\hline & 11 & 1 & 0.5 & 0.5 & 0.8 & 0.5 & 0.720 \\
\hline & 12 & 0.2 & 0.2 & 0.5 & 0.5 & 0.8 & 0.410 \\
\hline & 13 & 1 & 0.3 & 0.5 & 0.8 & 0.8 & 0.745 \\
\hline & 14 & 1 & 0.8 & 0.8 & 1 & 0.8 & 0.900 \\
\hline
\end{tabular}




\begin{tabular}{|c|c|c|c|c|c|c|c|}
\hline & 15 & 0.5 & 0.5 & 0.5 & 0.5 & 0.8 & 0.545 \\
\hline & 16 & 0.8 & 0.5 & 0.5 & 0.8 & 0.8 & 0.695 \\
\hline \multirow{16}{*}{ 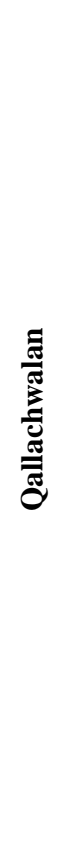 } & 1 & 0.3 & 0.5 & 0.8 & 0.8 & 1 & 0.625 \\
\hline & 2 & 0.3 & 0.8 & 0.8 & 0.5 & 0.8 & 0.580 \\
\hline & 3 & 1 & 0.8 & 0.8 & 1 & 1 & 0.930 \\
\hline & 4 & 1 & 0.5 & 0.8 & 1 & 1 & 0.900 \\
\hline & 5 & 0.2 & 1 & 0.8 & 0.8 & 0.8 & 0.610 \\
\hline & 6 & 0.5 & 0.5 & 0.8 & 1 & 1 & 0.725 \\
\hline & 7 & 1 & 0.5 & 0.8 & 1 & 1 & 0.900 \\
\hline & 8 & 1 & 0.5 & 0.8 & 1 & 1 & 0.900 \\
\hline & 9 & 1 & 0.5 & 0.5 & 0.8 & 1 & 0.795 \\
\hline & 10 & 1 & 0.5 & 0.5 & 0.8 & 0.8 & 0.765 \\
\hline & 11 & 0.8 & 0.3 & 0.5 & 0.3 & 0.8 & 0.600 \\
\hline & 12 & 1 & 0.3 & 0.5 & 0.2 & 0.8 & 0.655 \\
\hline & 13 & 1 & 0.5 & 0.8 & 0.5 & 0.8 & 0.795 \\
\hline & 14 & 0.3 & 0.2 & 0.5 & 0.2 & 0.8 & 0.400 \\
\hline & 15 & 1 & 0.3 & 0.8 & 1 & 1 & 0.880 \\
\hline & 16 & 1 & 0.2 & 0.8 & 0.5 & 0.8 & 0.765 \\
\hline
\end{tabular}

Table 6: maximum permissible soil loss rate for the study soils based on soil depth and aggregate score

\begin{tabular}{|c|c|c|c|c|c|}
\hline Site & Grid point & Soil depth $(\mathrm{cm})$ & $\begin{array}{l}\text { Aggregate } \\
\text { score (Q) }\end{array}$ & $\begin{array}{l}\text { Soil } \\
\text { group }\end{array}$ & $\begin{array}{l}\text { Maximum soil } \\
\text { loss rate } \\
\left(\mathrm{Mg} \mathrm{ha}^{-1} \mathrm{yr}^{-1}\right)\end{array}$ \\
\hline \multirow{16}{*}{ 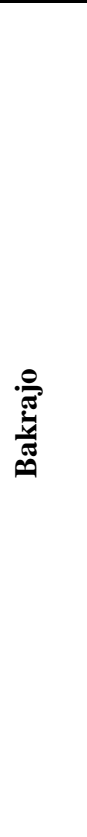 } & 1 & $25-50$ & 0.900 & 3 & 7.5 \\
\hline & 2 & $>150$ & 0.765 & 3 & 12.5 \\
\hline & 3 & $>150$ & 0.455 & 2 & 12.5 \\
\hline & 4 & $>150$ & 0.695 & 3 & 12.5 \\
\hline & 5 & $>150$ & 0.755 & 3 & 12.5 \\
\hline & 6 & $>150$ & 0.590 & 2 & 12.5 \\
\hline & 7 & $>150$ & 0.720 & 3 & 12.5 \\
\hline & 8 & $>150$ & 0.560 & 2 & 12.5 \\
\hline & 9 & $>150$ & 0.725 & 3 & 12.5 \\
\hline & 10 & $>150$ & 0.750 & 3 & 12.5 \\
\hline & 11 & $>150$ & 0.720 & 3 & 12.5 \\
\hline & 12 & $>150$ & 0.410 & 2 & 12.5 \\
\hline & 13 & $>150$ & 0.745 & 3 & 12.5 \\
\hline & 14 & $>150$ & 0.900 & 3 & 12.5 \\
\hline & 15 & $>150$ & 0.545 & 2 & 12.5 \\
\hline & 16 & $>150$ & 0.695 & 3 & 12.5 \\
\hline \multirow{3}{*}{ 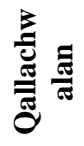 } & 1 & $100-150$ & 0.625 & 2 & 10 \\
\hline & 2 & $25-50$ & 0.580 & 2 & 5 \\
\hline & 3 & $50-100$ & 0.930 & 3 & 10 \\
\hline
\end{tabular}




\begin{tabular}{|lllll}
\hline 4 & $50-100$ & 0.900 & 3 & 10 \\
\hline 5 & $25-50$ & 0.610 & 2 & 5 \\
\hline 6 & $25-50$ & 0.725 & 3 & 7.5 \\
\hline 7 & $25-50$ & 0.900 & 3 & 7.5 \\
\hline 8 & $25-50$ & 0.900 & 3 & 7.5 \\
\hline 9 & $25-50$ & 0.795 & 3 & 7.5 \\
\hline 10 & $25-50$ & 0.765 & 3 & 7.5 \\
\hline 11 & $25-50$ & 0.600 & 2 & 5 \\
\hline 12 & $<25$ & 0.655 & 2 & 2.5 \\
\hline 13 & $25-50$ & 0.795 & 3 & 7.5 \\
\hline 14 & $<25$ & 0.400 & 2 & 2.5 \\
\hline 15 & $<25$ & 0.880 & 3 & 7.5 \\
\hline 16 & $<25$ & 0.765 & 3 & 7.5 \\
\hline
\end{tabular}

\section{CONCLUSION}

Generally most of the estimated soil tolerance limit for Bakrajo site was greater than Qallachwalan site. Most of Bakrajo soils depth in exceeds $150 \mathrm{~cm}$. So, it didn't need any conservation planning except continuous monitoring of the soil condition. In Qallachwalan site there was a large variety of the soils depth ranged from less than $25 \mathrm{~cm}$ to $150 \mathrm{~cm}$. This is means that need for numerous different conservation planning to control the soil erosion. The estimated soil erodibility for the two studied sites was ranged between low to moderate due to high content of clay particles and organic matter. The most aggregate score in Bakrajo was excess 0.66 which described soils under group 3, but in Qallachwalan site it was ranged between 0.33 and 0.66 and the soil was described under as group 2. In general the soil of Bakrajo site is in a best condition respect to water erosion risks than Qallachwalan soil site.

\section{REFERENCE}

[1] R. Lal, "Degradation and resilience of soils," Philosophical Transactions of the Royal Society of London. Series B: Biological Sciences, vol. 352, pp. 997-1010, 1997.

[2] H. Moehansyah, B. L. Maheshwari, and J. Armstrong, "Field evaluation of selected soil erosion models for catchment management in Indonesia," Biosystems Engineering, vol. 88, pp. 491-506, 2004.

[3] E. Karas and I. Oguz, "A new approach to determine land use planning and soil conservation measures based on soil erosion classification," Carpathian Journal of Earth and Environmental Sciences, vol. 10, pp. $145-158,2015$

[4] D. D. Bai ZG, Olsson L, Schaepman ME, "Global assessment of land degradation and improvement, identification by remote sensing," Wageningen Report 2008/01, ISRIIC, 2008.

[5] C. DeLong, R. Cruse, and J. Wiener, "The soil degradation paradox: Compromising our resources when we need them the most," Sustainability, vol. 7, pp. 866-879, 2015.

[6] A. Shiferaw, "Estimating soil loss rates for soil conservation planning in the Borena Woreda of South Wollo Highlands, Ethiopia," Journal of Sustainable Development in Africa, vol. 13, pp. 87-106, 2011.

[7] D. O. Mohammed, "Soil tolerance limit as a useful guide for prioritization of conservation planning of selected watersheds in Chamchamal area," M.Sc, soil and water sciences, University of sulaimani, College of agricultural sciences, 2017.

[8] R. Lal, Soil conservation for C sequestration. West lafayette, 2001.

[9] D. a. C. W. M. Gabriels, "Human-indused land degradation. land use, land cover and soil sciences," UNESCO-EOLSS, vol. 3,2002, 2002.

[10] A. Conacher, "Land degradation and desertification: history, nature, causes, consequences, and solutions," Theme, vol. 6, 2004.

[11] S. K. Jain, S. Kumar, and J. Varghese, "Estimation of soil erosion for a Himalayan watershed using GIS technique," Water Resources Management, vol. 15, pp. 41-54, 2001.

[12] D. Pimentel, "Soil erosion: a food and environmental threat," Environment, development and sustainability, vol. 8, pp. 119-137, 2006.

[13] N. Gupta, Zahn. M.M. Coppens, K.A. Joiner and D.R. voelker, and j., "Biochem. 2005," p. 163, Apr 22; 280(16) 2005. 
[14] D. Mandal and K. Tripathi, "Soil erosion limits for Lakshadweep Archipelago," Current Science (00113891), vol. 96, 2009

[15] A. T. O'geen and L. J. Schwankl, "Understanding soil erosion in irrigated agriculture," 2006

[16] A. Novara, L. Gristina, F. Guaitoli, A. Santoro, and A. Cerdà, "Managing soil nitrate with cover crops and buffer strips in Sicilian vineyards," Solid Earth, vol. 4, pp. 255-262, 2013.

[17] G. Zhao, X. Mu, Z. Wen, F. Wang, and P. Gao, "Soil erosion, conservation, and eco-environment changes in the Loess Plateau of China," Land Degradation \& Development, vol. 24, pp. 499-510, 2013.

[18] X. Duan, X. Shi, Y. Li, R. Li, and D. Fen, "A new method to calculate soil loss tolerance for sustainable soil productivity in farmland. Agron," Sustain. Dev, vol. 37, 2017.

[19] D. Mandal and V. Sharda, "Assessment of permissible soil loss in India employing a quantitative biophysical model," Current Science(Bangalore), vol. 100, pp. 383-390, 2011.

[20] D. McCormack, K. Young, and L. Kimberlin, "Current criteria for determining soil loss tolerance," Determinants of soil loss tolerance, pp. 95-111, 1982.

[21] J. Botschek, P. Sauerborn, A. Skowronek, and R. Wolff, "Tolerierbarer Bodenabtrag und BodenbildungKonzepte und Perspektiven," Mitt. Dtsch. Bodenkdl. Ges, vol. 83, pp. 87-90, 1997.

[22] R. Lal, "Agronomic consequences of soil erosion," Soil erosion at multiple scales, 1998.

[23] S. USDA, "National soils handbook," Soil Conservation Service, Washington, DC, USA, 1973.

[24] N. K. Lenka, D. Mandal, and S. Sudhishri, "Permissible soil loss limits for different physiographic regions of West Bengal," Current Science, pp. 665-670, 2014

[25] J. Poesen and H. Lavee, "Rock fragments in top soils: significance and processes," Catena, vol. 23, pp. 128, 1994.

[26] D. Mandal, K. Dadhwal, O. Khola, and B. Dhyani, "Adjusted T values for conservation planning in Northwest Himalayas of India," Journal of soil and water conservation, vol. 61, pp. 391-397, 2006.

[27] K. S. Hussein, "Conservation planning for Bastura catchment based on detection of erosion risk prone areas " M.Sc, soil and water sciences, University of salahaddin college of agricultural scienes, 2016.

[28] L. C. Johnson, "Soil loss tolerance: fact or myth?," Journal of soil and water conservation, vol. 42, pp. $155-160,1987$.

[29] NRCS, "The soil tolerance limit was computed for each site on the basis of soil group versus depth matrix," ed, 1999.

[30] J. Kessler and R. Oosterbaan, "Determining hydraulic conductivity of soils," Drainage principles and applications, vol. 3, pp. 252-296, 1974.

[31] A. Klute, Water retention: Laboratory methods, Klute ( ed.) ed. Maddison WI, 1986

[32] G. R. A. a. H. Blake., K.H, Bulk density in method of soil analysis, Part physical and mineralogical methods. 2nd 1986.

[33] L. Allison, "Organic Carbon 1," Methods of soil analysis. Part 2. Chemical and microbiological properties, pp. 1367-1378, 1965.

[34] M. Jackson, "Soil chemical analysis prentice Hall," Inc., Englewood Cliffs, NJ, vol. 498, 1958

[35] W. H. Wischmeier and D. D. Smith, Predicting rainfall erosion losses: a guide to conservation planning: Science and Education Administration, US Department of Agriculture, 1978.

[36] K. S. Qadir, "Study of erodibility of soils in Iraqi Kurdistan region," As a partial fulfillment of the requerments for the degree of master of science, A thesis submitted to the council of college of agriculture University of Sulaimani, 2001.

[37] T. C. a. B. Baruah, H.P., A textbook of soil analysis. Vishal Printers, Delhi110032., 1999.

[38] S. S. Staff, "Soil Survey Mnual," Bureau of Plant Industry, 1969.

[39] P. Bhattacharyya, D. Mandal, V. Bhatt, and R. Yadav, "A quantitative methodology for estimating soil loss tolerance limits for three states of northern India," Journal of sustainable agriculture, vol. 35, pp. 276292, 2011 